\title{
Coronary Shear Stress after Implantation of Bioresorbable Scaffolds - a Modern Interdisciplinary Concept at the Border between Interventional Cardiology and Cardiac Imaging
}

\author{
Dan Păsăroiu1, Zsolt Parajkó', Ionuț Ferenț ${ }^{1}$, Diana Opincariu², Annabell Benedek² \\ ${ }^{1}$ Center of Advanced Research in Multimodality Cardiac Imaging, Cardio Med Medical Center, Târgu Mureș, Romania \\ 2 University of Medicine, Pharmacy, Science and Technology, Târgu Mureș, Romania
}

\section{CORRESPONDENCE}

\section{Zsolt Parajkó}

Str. 22 Decembrie 1989 nr. 76

540124 Târgu Mureș, Romania

Tel: +40 265217333

E-mail: parajko.zsolt@gmail.com

\section{ARTICLE HISTORY}

Received: January 15, 2019

Accepted: February 20, 2019

Dan Păsăroiu • Str. 22 Decembrie 1989 nr. 76, 540124 Târgu Mures, Romania. Tel: +40 265217 333, E-mail: dan.pasaroiu@yahoo.com

lonuț Ferenț • Str. 22 Decembrie 1989 nr. 76, 540124 Târgu Mureș, Romania. Tel: +40 265217 333, E-mail: ionutferent2013@gmail.com

Diana Opincariu • Str. Gheorghe Marinescu nr. 50, 540136 Târgu Mureș, Romania. Tel: +40 265212 111, E-mail: diana.opincariu@yahoo.ro

Annabell Benedek • Str. Gheorghe Marinescu nr. 50, 540136 Târgu Mureș, Romania. Tel: +40 265212 111,

E-mail: annabell.benedek@yahoo.com

\begin{abstract}
Bioresorbable scaffolds/stents offer new and exciting perspectives in the treatment of patients with acute coronary syndromes, especially after the recent development of invasive imaging techniques, such as optical coherence tomography, which allow complete assessment of vascu-lar segments. A particular advantage of bioresorbable scaffolds is that once the biosorption of the scaffold is complete, the vascular segment regains its normal physiological functions, thus eliminating the risk of late complications. New studies show the importance of shear stress in the progression of vascular atherosclerosis or in accelerating endothelial turnover. Based on the current knowledge in this field, a future standardized determination of shear stress may help in the long-term follow-up of patients that have suffered or are at risk of developing an acute coronary syndrome.
\end{abstract}

Keywords: acute coronary syndrome, bioresorbable scaffolds, shear stress, atherosclerosis

\section{INTRODUCTION}

Atherosclerosis is a chronic, inflammatory, systemic disease, which affects particularly the arteries with large and middle caliber., ${ }^{1,2}$ Even though the systemic risk factors for atherosclerosis-dyslipidemia, smoking, high blood pressure, diabetes, chronic inflammatory disorders, genetic predisposition-affect the entire coronary tree, the atherosclerotic lesions are formed in specific segments of the coronary arteries such as the origin of a coronary branch, the external part of a bifurcation, or the inner wall of a vascular curvature, leading to a hemodynamic impairment characterized by a turbulent flow at this level. ${ }^{3}$ Local factors, especially hemodynamic forces, play an important role in the regional disposition of 
atherosclerosis. ${ }^{4-7}$ These local hemodynamic disturbances include endothelial shear stress (ESS), which is generated by the blood flow and the tangential wall tension, the first of which has a fundamental role in development and progression of atherosclerosis.

\section{ENDOTHELIAL SHEAR STRESS}

The earliest data regarding the influence of ESS on the location of atherosclerotic lesions was described by Caro et al. four decades ago. ${ }^{8}$ Later on, computational simulations of fluid dynamics in autopsy-based models of the coronary vasculature, ${ }^{9}$ the carotid bifurcations, ${ }^{10}$ and of the distal part of the abdominal aorta ${ }^{11}$ indicated that areas with decreased shear stress develop atherosclerotic lesions.

Several in vivo animal experiments also supported the atherogenic role of decreased ESS. ${ }^{12-14}$ In vivo investigations on human subjects, using combined intravascular ultrasound (IVUS) or magnetic resonance imaging (MRI) and computational fluid dynamics have established the role of decreased ESS in the evolution of atherosclerotic lesions in various vascular sites. ${ }^{15,16}$ Current molecular and cellular research has clarified in detail the pathophysiological mechanism involved in the development of atherosclerosis on the basis of increased ESS, leading to the formation of fibroatheromas with a thin fibrotic layer, presumed to be "vulnerable plaques", responsible for triggering acute coronary syndromes (ACS). ${ }^{17-21}$

A central determinant in the development and evolution of the atheromatous process is the local remodeling of the arterial wall that occurs as a response to plaque progression and growth, influencing both the natural history as well as the clinical evolution of individuals affected by atherosclerotic disease. The vascular remodeling process is indisputably affected by local hemodynamic factors. ${ }^{15,21,22-24}$ ESS represents the tangential force resulting from the friction of blood flow on the endothelial layer of the arterial wall, being expressed in unit of force/unit of surface $\left(\mathrm{N} / \mathrm{m}^{2}\right.$ or Pascal $[\mathrm{Pa}]$ or dyne $/ \mathrm{cm}^{2} ; 1 \mathrm{~N} / \mathrm{m}^{2}=1 \mathrm{~Pa}$ $=10$ dyne $\left./ \mathrm{cm}^{2}\right) \cdot{ }^{25,26}$ ESS is correlated with the product of blood viscosity $(\mu)$ and the spatial gradient of blood velocity in the wall $(\mu \times \mathrm{dv} / \mathrm{dy})$.

The particularities of a fluid streaming through a tube depend on flow velocity and on the presence of geometric irregularities or obstructions. Fluid flow can be either laminar or turbulent. ${ }^{25,27}$ Laminar flow is characterized by a linear flow, which subsequently can be divided into laminar flow with undisturbed debit, described by a linear flow line, and turbulent laminar flow, which is characterized by areas with reversed flow or a circumferential vortex..$^{25,28}$ In case of turbulent flow, velocity at any point continuously varies in time, even if the flow is stable.

For a certain geometry, both turbulent and laminar flow are determined by the Reynolds number (Re): for low values the flux is laminar, while for high values (typically above 2,000), the flow is turbulent., 70,29

Certain vascular segments, such as the branching site of arteries, vascular curvatures, bifurcations, as well as downstream from an obstruction, are more prone to develop atheromatous lesions. Even with the systemic effect of cardiovascular risk factors, only a small percentage of coronary lesions lead to an acute clinical event. Therefore, local factors such as ESS are required in the process of development and progression of atherosclerosis.

Arterial geometry determines the shear stress model on the respective arterial segment. The presence of bifurcations, curves, or obstructions modifies flow and the pattern of shear stress. Therefore, intricate interactions between blood flow, viscosity, and arterial geometry generate different patterns of ESS, characterized by direction (unidirectional, bidirectional) and variable degrees of magnitude (low, moderate, high)..$^{30}$

Moderate shear stress varies between 1.5-3.0 Pa during a cardiac cycle, being identified in almost linear arterial segments, where unidirectional flow is present, with protective effects regarding atherosclerosis. Increased values of shear stress are considered above $3 \mathrm{~Pa}$ and are usually measured at the level of a stenotic lesion caused by an atherosclerotic plaque, while a decreased ESS (below 1-1.5 Pa), with a non-turbulent unidirectional flow, generally appears in the inner region of a vascular curve, as well as the upstream region of a stenotic plaque. ${ }^{31,32} \mathrm{~A}$ low oscillating ESS is characterized by a bidirectional (retrograde) flow, being observed at the level of a collateral branch ostium, downstream of a stenotic lesion, or at the lateral walls of bifurcations. Low and/or oscillated shear stress promotes atherogenesis, being a crucial factor in the development of focal atheromatous plaques. ${ }^{5,32}$

Biomechanical factors contribute substantially to the process of vulnerabilization of atheromatous plaques, with subsequent development of an acute cardiovascular or cerebrovascular event via plaque erosion, rupture, and subsequent thrombosis. Atherosclerotic plaques are characterized by a lipid-rich necrotic core and a thin fibrous cap which delineates the core from the vascular lumen, preventing contact between its thrombogenic content and the blood flow. Plaque rupture is caused by thinning of the fibrous layer, which makes it susceptible to the effect of hemodynamic mechanical forces. The concentration of col- 
lagen in the plaque cap is crucial for the resistance of the fiber layer against these forces. ${ }^{33,34}$

Excessive and expansive plaque remodeling with low shear stress and intense matrix metalloproteinase (MMP) activity has been linked to a high vulnerability degree of atheromatous plaques. ${ }^{35-37}$ The underlying mechanisms that are accountable for plaque erosion have not been as profoundly studied as the processes that may lead to plaque rupture. However, most plaque erosions occur in the downstream region of the atherosclerotic lesion, which is exposed and characterized by a low local ESS. Areas with decreased shear stress are characterized by increased endothelial cell turnover, endothelial cell apoptosis, and endothelial glycocalyx, which leads to endothelial denudation. Consequently, a reduced ESS is involved in the pathogenesis of plaque erosion. An increased proteolytic function of MMP and a reduced collagen synthesis in places with reduced ESS may influence the thinning of the fiber layer, which increases the risk of plaque rupture. ${ }^{38-40}$

The detrimental role of ESS in the initiation and progression of atherosclerosis shown in animal studies underlies the importance and need of a validated study on human subjects. The pattern of shear stress depends on the arterial geometry and the type of blood flow, and a precise 3D reconstruction of vascular geometry and coronary blood flow is the premise for the estimation of ESS. These data are obtained using intravascular imaging methods such as IVUS and optical coherence tomography (OCT), as well as noninvasive imaging methods such as computed tomography angiography.

Early studies on human subjects have been published a decade ago, demonstrating that ESS is a significant factor in the progression of atherosclerotic plaques, as well as in the process of vascular remodeling. ${ }^{15,22}$ Stone et al. stated that the progression of atheromatous plaques was observed almost exclusively in areas with decreased ESS and may be associated with an expansive or constrictive remodeling process of the underlying vasculature. Further studies conducted by Samady et al. supported the role of shear stress in coronary disease as well, linking the progression of plaques with low values of ESS. These researches have contributed considerably to investigating and clarifying the role of ESS in the initiation and development of atherosclerosis; however, these studies were limited by a low number of included subjects. Other studies have focused on the evaluation of shear stress in interventional cardiology and its dynamics following stent implantation procedures. Neointimal hyperplasia, neoatherosclerosis, and in-stent restenosis are the interventional cardiologist's enemies. ${ }^{41-43}$
Shear stress has recently been studied as an influencing factor on the prognosis and clinical evolution of patients following stent angioplasty. Stent implantation leads to endothelial and arterial wall damage, which will alter the local geometry and blood flow (flow separation, recirculation). ${ }^{44}$ After the introduction of drug-eluting stents, there has been a considerable decrease in the frequency of in-stent restenosis and neointimal hyperplasia, which had been relatively high in the era of bare-metal stents. Several studies sustain the theory according to which ESS leads to in-stent neointimal hyperplasia and neointimal neo-atherosclerosis, which requires the search for optimal positioning strategies and stent structure. ${ }^{45-47}$ Shear stress apparently does not influence the arterial wall under the stent struts, perhaps due to the altered, compressed arterial structure. ${ }^{45,48}$

\section{THE BENEFITS OF BIORESORBABLE STENTS}

Bioresorbable stents have several potential advantages over drug-eluting stents, including:

1. Reduction of adverse events such as stent thrombosis: the stent itself is temporary, the release of active substance is secured by the stent until the vessel is healed, and there is no foreign material such as non-endothelialized stent struts or polymers of the active substance (which are triggers for intrastent thrombosis) that may persist for a prolonged period.

2. Removal of the rigid vascular binding by bioresorption can facilitate the recovery of vasomotricity, shear stress adaptability, and late vascular expansion. Furthermore, it can reduce the collateral ostial obstruction problems observed in metallic stents.

3. Reduction of bleeding complications: once the bioresorption of the temporary stent has been completed, the dual antiplatelet therapy may be suspended. This is a particularly relevant feature, as the elderly, with the highest risk of hemorrhagic complications, benefit from an increasing proportion of invasive interventions for the treatment of ischemic coronary artery disease. ${ }^{49}$ Furthermore, the premature discontinuation of dual antiplatelet therapy after the implantation of drug-eluting stents for any indication has been shown to be an independent predictor of intrastent thrombosis. ${ }^{50}$

4. Improvement of future therapeutic options: interventional therapy of complex multivascular coronary disease involves the use of multiple, long, 
drug-eluting stents. For example, in the SYNTAX trial, an average number of 4 stents were used, and in 1 out of 3 patients the implanted stents were longer than $100 \mathrm{~mm}$. In such cases, repetitive revascularization, either interventional or surgical, may be potentially challenging due to the metallic embossing formed by previously implanted drug-eluting stents. The use of bioresorbable stents would not restrain a future percutaneous revascularization procedure or any surgical interventions.

5. The possibility to use imaging techniques such as angiography, computed tomography (CT), or MRI for follow-up of stents. Right now, metallic stents make it difficult to interpret such images because they leave a metallic artefact. Poly-L-lactic acid/ amorphous calcium phosphate bioabsorbable stents are not metallic, thus they should not hinder the usage of CT or MRI; once bioresorption has been finalized, bioresorbable stents do not impair the use of CT or MRI for the evaluation of stent and vessel permeability. This could mean that such noninvasive imaging techniques could become an alternative to invasive imaging in the long-term follow-up of patients. ${ }^{50}$

6. The local release of active substances: the duration of bioresorption is influenced by the type of utilized polymer. A controlled release of multiple substances could be obtained through the early release of antiproliferative agents from the outer polymer layer of the stent, in conjunction with the late release of anti-inflammatory agents from polymers that are located in the stent structure.

7. Aid in decreasing patient concern regarding stent implantation, aiming to conquer the fears of patients who will live with this implant for the rest of their life. ${ }^{51}$

One of the biggest hopes concerning bioresorbable stents is that after bioresorption is complete, the stented vascular segment will regain its normal function and will be completely free of foreign bodies; this in fact minimizes the possibility of thrombotic events later on and eliminates the need for double antiplatelet treatment regiments on long term. Bioresorbable scaffolds could have the potential to eliminate certain factors that contribute to late stent thrombosis such as delayed epithelialization, chronic inflammatory response, and hypersensitivity local reaction. ${ }^{52} \mathrm{~A}$ lower incidence of stent thrombosis has been observed in patients treated with a biodegradable polymer stent versus a durable polymer stent $(0.4 \%$ vs. $1.8 \%$, $\mathrm{p}=0.004) .{ }^{53}$ Notably, a recently published study has found that patients undergoing simple coronary angioplasty are at risk of developing late stent thrombosis, which could indicate that bioresorbable stents cannot eliminate this complication entirely. ${ }^{54}$

Metallic stents seem to not protect the blood vessel against neoatherosclerosis or progression of plaques. It is postulated that the implantation of bioresorbable scaffolds could offer a coating that is symmetric and uniform, which, alongside the delayed expansion of the interior lumen and the absence of a permanent prosthesis, could help in the stabilization of vulnerable plaques and thus prevent future cardiovascular events. ${ }^{55}$ This is a very tempting idea, and it is supported by studies based on the concept of stabilizing plaques by stenting and by the fact that bioresorbable stents offer a coating that is fibrous, symmetric, circumferential, with a normally functioning endothelium, a delayed extension of the lumen and normal distribution of shear stress. 55

The IVUS analysis of ABSORB bioresorbable scaffolds between 6 months and 2 years has uncovered a significant reduction of plaques without modifying the structure of the vascular wall. ${ }^{56,57}$

\section{THE ADVANTAGES OF BIORESORBABLE STENTS IN RESTORING THE NORMAL BLOOD FLOW IN THE CORONARY ARTERIES}

Bioresorbable scaffolds are considered a very important leap in the field of percutaneous transluminal coronary angioplasty. 58 They have been conceived for the purpose of bypassing certain disadvantages of metallic drug-eluting stents such as, for example, the chronic local inflammatory reaction, the absence of physiological vascular mobility, late stent thrombosis, and, last but not least, the possibility of cardiovascular bypass further on. ${ }^{18,19,59,60}$

Bioresorbable scaffolds function in a three-phase system: revascularization, restoration, and resorption. In the first phase, bioresorbable stents are meant to mimic the characteristic of drug-eluting metal stents, this meaning the expansion of stents with minimum rebound and high radial force, and the controlled release of antiproliferative substances. Thus, in the restoration stage, vascular motricity is reestablished and the transitioning from an active support to a more passive one begins. The last stage, resorption, is characterized by degradation and metabolization of the stent. ${ }^{61}$

Stents have been developed to prevent and to manage the complications of percutaneous transluminal coronary angioplasty, mainly acute vascular obstruction determined 
by arterial dissection, elastic recoil, late constrictive remodeling, and neointimal proliferation. Ideally, the coverage provided by bioresorbable stents in the first months should be as good as the one provided by metallic stents. ${ }^{62}$

Poly-L-lactic acid is a biodegradable, thermoplastic, aliphatic polyester, which suffers autocatalytic hydrolytic degradation to normal lactic acid, which is then metabolized into carbon dioxide and water. Bioresorbable stents based on this kind of substance are made from a combination of semi-crystalline polymers (which provide mechanical strength) and amorphous polymers (which provide the ability to release the active substance at the desired time). The degradation process is influenced by the crystallization level of the polymers and can vary from 2 to 4 years. ${ }^{63}$

Metallic stents can alter the geometry and biomechanics of the blood vessel; furthermore, chronic irritation and turbulent blood flow favor neointimal proliferation and adverse effects. ${ }^{64,65}$ Bioresorbable scaffolds offer the potential of preserving vascular geometry. The ABSORB bioresorbable stent is more compliant than a metallic one, this in fact determines less lesions at the site of vascular angulations. ${ }^{56}$ It has been observed in 6- to 12-month follow-ups that bioresorbable stents tend to restore the normal configuration of the coronary vessel, as opposed to metallic stents which alter coronary geometry forever. ${ }^{66}$

A series of studies using drug-eluting stents have reported abnormal vasomotricity in the distal segment of the blood vessel after stenting, this limiting the blood flow and thus predisposing the patient to late in-stent thrombosis. Bioresorbable scaffold technology has been described as a reconstructive vascular therapy. After bioresorption, these stents promise the restoration of dynamic vasomotricity, pulsatility, distensibility and mechano-transduction, demonstrating the ability to transform mechanical forces into chemical signals (mediated by nitric oxide and prostacyclin). ${ }^{56}$ Cohort A from the ABSORB trial showed that the stented segment had vasomotricity after administering acetylcholine at 2 years after stent implantation. ${ }^{14}$

\section{SHEAR STRESS IN ATHEROSCLEROTIC PLAQUES TREATED WITH BIORESORBABLE STENTS}

A recent study has indicated the importance of hemodynamic factors in neointimal response after the implantation of ABSORB bioresorbable stents. This led to an improvement of stent design in order to make them more ergonomic. ${ }^{48}$ The same study suggested that the evaluation of the stented artery from the perspective of shear stress should be carried out by fusing images from OCT with invasive angiography, which are superior to the images resulted from fusing images provided by IVUS with angiography. ${ }^{67}$

Bioresorbable medical tools have been gaining ground in recent years; however, a lot of questions remain unanswered, mainly because it is not known how these devices will fade in the long run. These questions are especially important in bioresorbable coronary stents, in which late stent thrombosis may occur. ${ }^{68-71}$ The mechanism proposed for these kinds of complications imply dismantling of the polymer and late stent inflammation. ${ }^{72,73}$ However, there are other factors that collide when this kind of complication occurs, one being the local dynamic blood flow. Other factors that can be incriminated in stent thrombosis are neointimal abnormal regeneration, uncovered struts, and wrong placement of the stent. ${ }^{17,74}$ In some cases, local suboptimal hemodynamic characteristics, right after the implantation of a bioresorbable scaffold, could contribute to a bad neointimal proliferation, uncovered struts, and poor stent positioning. ${ }^{75}$

With the permanent presence of struts in the lumen, the stent is exposed to extreme shear stress, which activates the platelets. ${ }^{76}$ The distal regions are predisposed to lower shear stress and higher viscosity, in which case the activated thrombocytes can aggregate.

The dynamic attribute of the blood flow directly regulates vascular biology and influences the development of atherosclerosis. ${ }^{77,78}$ Abnormally high or low ESS has been correlated with the progression, vulnerability, and maybe even with the rupture of atherosclerotic plaques and subsequent thrombosis. ${ }^{21,79-81}$

Remarkably, due to the resorption of scaffold material in time, the coronary arteries that were treated with such devices develop a partial return of vasomotricity, which completes the latent lumen expansion, this way stabilizing the plaque. ${ }^{47,76,82,83}$ It is believed that some of these observations may be correlated with the normalization of blood flow after the implantation of bioresorbable scaffolds.

We must keep in mind the therapeutic objectives of this technique. The final goal can sound abstract and theoretical, but it has a name: endothelial shear stress. Normal shear stress has to be the main criteria for an optimal implantation; this means optimal stent apposition, no protrusion of struts in the vascular lumen that can disturb the blood flow, no significant difference between the diameter of the proximal and distal end of a stented segment (in other words the perfect incorporation of stents in the vascular wall), no asymmetry of the blood vessel, and a bioresorbable scaffold/artery ratio between 1 and $1.1 .^{84}$ In fact, only 
intravascular imaging techniques can accurately evaluate the criteria mentioned above for optimal implantation. Only OCT with a resolution of 20 microns can examine the blood vessel and the interaction with the bioresorbable stent for the required precision. ${ }^{84,85}$

The possibility of identifying a pathologic alteration of shear stress using computational simulations based on fluid dynamics in the coronary regions, after the implantation of a stent, as well as achieving dynamic simulations, could open up new horizons for percutaneous transluminal coronary revascularization.

\section{CONCLUSIONS}

Current knowledge suggests that low or oscillating shear stress has an important role in the development of atherosclerosis. Furthermore, the affected vascular segment has a higher endo-thelial turnover. Even though risk factors affect the entire vascular system, atherosclerotic le-sions develop only in certain areas such as arterial branching sites, curvatures, bifurcations, or distal from a stenotic lesion. This observation emphasizes the role of local hemodynamic fac-tors in the development and progression of atherosclerotic plaques.

The most important advantage of using bioresorbable scaffolds is that after bioresorption is completed, the affected segment regains its normal physiological functions. Other important advantages include a lower risk of major cardiac events or bleeding complications, associated with the possibility to use modern imaging techniques for stent follow-up.

\section{CONFLICT OF INTEREST}

Nothing to declare.

\section{REFERENCES}

1. Ross R. Atherosclerosis-an inflammatory disease. $N$ Engl J Med. 1999;340:115-126.

2. Hansson GK. Inflammation, atherosclerosis, and coronary artery disease. N Engl J Med. 2005;352:1685-1695.

3. VanderLaan PA, Reardon CA, Getz GS. Site specificity of atherosclerosis: site-selective responses to atherosclerotic modulators. Arterioscler Thromb Vasc Biol. 2004;24:12-22.

4. Malek AM, Alper SL, Izumo S. Hemodynamic shear stress and its role in atherosclerosis. JAMA. 1999;282:2035-2042.

5. Stone P, Coskun A, Yeghiazarians $Y$, et al. Prediction of sites of coronary atherosclerosis progression: in vivo profiling of endothelial shear stress, lumen, and outer vessel wall characteristics to predict vascular behavior Curr Opin Cardiol. 2003:18:458-470.

6. Gimbrone MA Jr., Topper JN, Nagel T, Anderson KR, Garcia-Cardena G Endothelial dysfunction, hemodynamic forces, and atherogenesis. Ann N Y Acad Sci. 2000:902:230-239.

7. Cunningham KS, Gotlieb Al. The role of shear stress in the pathogenesis of atherosclerosis. Lab Invest. 2005;85:9-23.

8. Caro CG, Fitz-Gerald JM, Schroter RC. Arterial wall shear and distribution of early atheroma in man. Nature. 1969;223:1159-1160.

9. Asakura T, Karino T. Flow patterns and spatial distribution of atherosclerotic lesions in human coronary arteries. Circ Res. 1990;66:1045-1066.

10. Ku DN, Giddens DP, Zarins CK, Glagov S. Pulsatile flow and atherosclerosis in the human carotid bifurcation. Positive correlation between plaque location and low oscillating shear stress. Arteriosclerosis. 1985;5:293-302.

11. Moore JE Jr., Xu C, Glagov S, Zarins CK, Ku DN. Fluid wall shear stress measurements in a model of the human abdominal aorta: oscillatory behavior and relationship to atherosclerosis. Atherosclerosis. 1994;110:225-240

12. Gambillara V, Chambaz C, Montorzi G, Roy S, Stergiopulos N, Silacci P. Plaque-prone hemodynamics impair endothelial function in pig carotid arteries. Am J Physiol Heart Circ Physiol. 2006;290:H2320-2328.

13. Cheng $C$, van Haperen $R$, de Waard $M$, et al. Shear stress affects the intracellular distribution of eNOS: direct demonstration by a novel in vivo technique. Blood. 2005;106:3691-3698.

14. Buchanan JR Jr., Kleinstreuer C, Truskey GA, Lei M. Relation between non-uniform hemodynamics and sites of altered permeability and lesion growth at the rabbit aorto-celiac junction. Atherosclerosis. 1999;143:27-40.

15. Stone PH, Coskun AU, Kinlay S, et al. Effect of endothelial shear stress on the progression of coronary artery disease, vascular remodeling, and in-stent restenosis in humans: in vivo 6-month follow-up study. Circulation. 2003;108:438-44.

16. Wentzel JJ, Corti R, Fayad ZA, et al. Does shear stress modulate both plaque progression and regression in the thoracic aorta? Human study using serial magnetic resonance imaging. J Am Coll Cardiol. 2005;45:846854.

17. Chatzizisis YS, Jonas M, Coskun AU. Low endothelial shear stress (ESS) is responsible for the heterogeneity and severity of coronary atherosclerotic plaques: an in-vivo IVUS natural history study (abstr). Circulation. 2006;114:1123

18. Chatzizisis YS, Jonas M, Coskun AU. Low endothelial shear stress (ESS) predicts the development of high-risk coronary atherosclerotic plaques: a correlative IVUS and histopathology natural history study (abstr). J Am Coll Cardiol. 2007;49:Suppl A:334A.

19. Chatzizisis YS, Jonas M, Coskun AU, Low endothelial shear stress (ESS) leads to expansive remodeling of atherosclerotic coronary subsegments: an in-vivo follow-up IVUS study (abstr). J Am Coll Cardiol. 2007;49:Supp|A:335.

20. Cheng C, Tempel D, van Haperen R, et al. Atherosclerotic lesion size and vulnerability are determined by patterns of fluid shear stress. Circulation. 2006;113:2744-2753

21. Gambillara V, Montorzi G, Haziza-Pigeon C, Stergiopulos N, Silacci P. Arterial wall response to ex vivo exposure to oscillatory shear stress. $J$ Vasc Res. 2005:42:535-544.

22. Stone PH, Coskun AU, Kinlay S, et al. Regions of low endothelial shear stress are sites where coronary plaque progress and vascular remodeling occurs in humans: an in-vivo serial study. Eur Heart J. 2007:28:705-710.

23. Wentzel JJ, Janssen E, Vos J, et al. Extension of increased atherosclerotic wall thickness into high shear stress regions is associated with loss of compensatory remodeling. Circulation. 2003:108:17-23.

24. Wentzel JJ, Kloet J, Andhyiswara I, et al. Shear-stress and wall-stress regulation of vascular remodeling after balloon angioplasty: effect of matrix metalloproteinase inhibition. Circulation. 2001;104:91-96.

25. Nichols WW, O'Rourke MF. McDonald's Blood Flow in Arteries: Theoretical Experimental and Clinical Principles. 5th edition. London: A Hodder Arnold Publication, 2005

26. Slager CJ, Wentzel JJ, Gijsen FJ, et al. The role of shear stress in the generation of rupture-prone vulnerable plaques. Nat Clin Pract Cardiovasc Med. 2005;2:401-407.

27. Munson BR, Young DF, Okiishi TH. Fundamentals of Fluid Mechanics Canada: John Wiley \& Sons, 1990.

28. Feldman CL, llegbusi OJ, Hu Z, Nesto R, Waxman S, Stone PH. Determination of in vivo velocity and endothelial shear stress patterns with phasic flow in human coronary arteries: a methodology to predict progression of coronary atherosclerosis. Am Heart J. 2002;143:931-939.

29. Maclsaac Al, Thomas JD, Topol EJ. Toward the quiescent coronary plaque. J Am Coll Cardiol. 1993:22:1228-1241.

30. Katranas SA, Kelekis AL, Antoniadis AP, Ziakas AG, Giannoglou GD Differences in stress forces and geometry between left and right coronary artery: a pathophysiological aspect of atherosclerosis heterogeneity. Hellenic J Cardiol. 2015:56:217e223.

31. Wentzel JJ, Chatzizisis YS, Gijsen FJ, Giannoglou GD, Feldman CL, Stone $\mathrm{PH}$. Endothelial shear stress in the evolution of coronary atherosclerotic plaque and vascular remodelling: current understanding and remaining 
questions. Cardiovasc Res. 2012;96:234e243.

32. Chatzizisis YS, Coskun AU, Jonas M, Edelman ER, Feldman CL, Stone $\mathrm{PH}$. Role of endothelial shear stress in the natural history of coronary atherosclerosis and vascular remodeling: molecular, cellular, and vascular behavior. J Am Coll Cardiol. 2007;49:2379e2393.

33. Kwak BR, Back M, Bochaton-Piallat ML, et al. Biomechanical factors in atherosclerosis: mechanisms and clinical implications. Eur Heart J. 2014;35:3013-3020.

34. Tousoulis D, Papageorgiou N, Synetos A, Stefanadis C. Assessing vulnerable plaque: is shear stress enough? Int J Cardiol. 2014; 172:e135-e138.

35. Koskinas KC, Sukhova GK, Baker AB, et al. Thin-capped atheromata with reduced collagen content in pigs develop in coronary arterial regions exposed to persistently low endothelial shear stress. Arterioscler Thromb Vasc Biol. 2013;33:1494-1504

36. Chatzizisis YS, Baker AB, Sukhova GK, et al. Augmented expression and activity of extracellular matrix-degrading enzymes in regions of low endothelial shear stress colocalize with coronary atheromata with thin fibrous caps in pigs. Circulation. 2011;123:621-630.

37. Koskinas KC, Feldman CL, Chatzizisis YS, et al. Natural history of experimental coronary atherosclerosis and vascular remodeling in relation to endothelial shear stress: a serial, in vivo intravascular ultrasound study. Circulation. 2010;121:2092-2101.

38. Xu Q. Disturbed flow-enhanced endothelial turnover in atherosclerosis Trends Cardiovasc Med. 2009;19:191-195.

39. Quillard T, Araujo HA, Franck G, Shvartz E, Sukhova G, Libby P. TLR2 and neutrophils potentiate endothelial stress, apoptosis and detachment: implications for superficial erosion. Eur Heart J. 2015;36:1394-1404.

40. Cicha I, Worner A, Urschel K, et al. Carotid plaque vulnerability: a positive feedback between hemodynamic and biochemical mechanisms. Stroke. 2011:42:3502-3510

41. Corban MT, Eshtehardi P, Suo J, et al. Combination of plaque burden, wall shear stress, and plaque phenotype has incremental value for prediction of coronary atherosclerotic plaque progression and vulnerability. Atherosclerosis. 2014;232:271-276.

42. Eshtehardi P, McDaniel MC, Suo J, et al. Association of coronary wall shear stress with atherosclerotic plaque burden, composition, and distribution in patients with coronary artery disease. J Am Heart Assoc. 2012;1:e002543.

43. Samady H, Eshtehardi P, McDaniel MC, et al. Coronary artery wall shear stress is associated with progression and transformation of atherosclerotic plaque and arterial remodeling in patients with coronary artery disease. Circulation. 2011;124:779-788.

44. Otsuka F, Finn AV, Yazdani SK, Nakano M, Kolodgie FD, Virmani R. The importance of the endothelium in atherothrombosis and coronary stenting. Nat Rev Cardiol. 2012;9:439-453.

45. Bourantas CV, Papafaklis MI, Kotsia A, et al. Effect of the endothelial shear stress patterns on neointimal proliferation following drug-eluting bioresorbable vascular scaffold implantation: an optical coherence tomography study. JACC Cardiovasc Interv. 2014;7:315-324.

46. Wentzel JJ, Krams R, Schuurbiers JC, et al. Relationship between neointimal thickness and shear stress after wall stent implantation in human coronary arteries. Circulation. 2001;103:1740-1755.

47. Brugaletta S, Heo JH, Garcia-Garcia HM, et al. Endothelial-dependent vasomotion in a coronary segment treated by ABSORB everolimus-eluting bioresorbable vascular scaffold system is related to plaque composition at the time of bioresorption of the polymer: indirect finding of vascular reparative therapy? Eur Heart J. 2012;33:1325-1333.

48. Papafaklis MI, Bourantas CV, Theodorakis PE, et al. The effect of shear stress on neointimal response following sirolimus and paclitaxel-eluting stent implantation compared with bare-metal stents in humans. JACC Cardiovasc Interv. 2010;3:1181-1189.

49. Nikolsky E, Mehran R, Dangas G, et al. Development and validation of a prognostic risk score for major bleeding in patients undergoing percutaneous coronary intervention via the femoral approach. Eur Heart J. 2007;28:1936-1945.

50. Van Werkum JW, Heestermans AA, Zomer AC, et al. Predictors of coronary stent thrombosis: The Dutch stent thrombosis registry. J Am Coll Cardiol. 2009;53:1399-1409.

51. Spuentrup E, Ruebben A, Mahnken A, et al. Artifact-free coronary magnetic resonance angiography an coronary vessel wall imaging in the presence of a new, metallic coronary magnetic resonance imaging stent. Circulation. 2005;111:1019-1026.

52. Di Mario C, Borgia F. Assimilating the current clinical data of fully bioabsorbable stents. Eurolntervention. 2009;5:F103-F108.
53. Stefanini GG, Kalesan B, Serruys PW, et al. Long-term clinical outcomes of biodegradable polymer biolimus-eluting stents versus durable polymer sirolimus-eluting stents in patients with coronary artery disease (LEADERS): 4 year follow-up of a randomised non-inferiority trial. Lancet. 2011;378:1940-1948.

54. Yamaji K, Kimura T, Morimoto T, et al. Very long-term (15 to 23 years) outcomes of successful balloon angioplasty com- pared with bare metal coronary stenting. J Am Heart Assoc. 2012;1:e004085.

55. Brugaletta S, Gogas BD, Garcia-Garcia HM, et al. Vascular compliance changes of the coronary vessel wall after bioresorbable vascular scaffold implantation in the treated and adjacent segments. Circ J. 2012;76:16161623.

56. Gomez-Lara J, Garcia-Garcia HM, Onuma Y, et al. A comparison of the conformability of everolimus-eluting bioresorbable vascular scaffolds to metal platform coronary stents. JACC Cardiovasc Interv. 2010;3:1190-1198.

57. Ormiston JA, Serruys PW, Onuma Y, et al. First serial assessment at 6 months and 2 years of the second generation of absorb everolimuseluting bioresorbable vascular scaffold: a multi-imaging modality study. Circ Cardiovasc Interv. 2012;5:620-632

58. Bourantas CV, Zhang Y, Farooq V, Garcia-Garcia HM, Onuma Y, Serruys PW. Bioresorbable scaffolds: current evidence and ongoing clinical trials. Curr Cardiol Rep. 2012;14:626-634.

59. Nakazawa G, Ladich E, Finn AV, Virmani R. Pathophysiology of vascular healing and stent mediated arterial injury. Eurolntervention. 2008;4:C7C10.

60. Nakazawa G, Otsuka F, Nakano M, et al. The pathology of neoatherosclerosis in human coronary implants bare-metal and drugeluting stents. J Am Coll Cardiol. 2011;57:1314-1322.

61. Oberhauser JP, Hossainy S, Rapoza RJ. Design principles and performance of bioresorbable polymeric vascular scaffolds. Eurolntervention. 2009;5: F15-F22.

62. Iqbal J, Sumaya W, Tatman V, et al. Incidence and predictors of stent thrombosis: a single-centre study of 5,833 consecutive patients undergoing coronary artery stenting. Eurolntervention. 2013;9:62-69.

63. Onuma Y, Serruys PW. Bioresorbable scaffold: the advent of a new era in percutaneous coronary and peripheral revascularization? Circulation. 2011;123:779-797.

64. Bourantas CV, Raber L, Zaugg S, et al. Impact of local endothelial shear stress on neointima and plaque following stent implantation in patients with ST-elevation myocardial infarction: A subgroup-analysis of the COMFORTABLE AMI-IBIS 4 trial. Int J Cardiol. 2015;186:178-85.

65. Gyongyosi M, Yang P, Khorsand A, Glogar D. Longitudinal straightening effect of stents is an additional predictor for major adverse cardiac events. Austrian Wiktor Stent Study Group and European Paragon Stent Investigators. J Am Coll Cardiol. 2000;35:1580-1589.

66. Gomez-Lara J, Brugaletta S, Farooq V, et al. Angiographic geometric changes of the lumen arterial wall after bioresorbable vascular scaffolds and metallic platform stents at 1-year follow-up. JACC Cardiovasc Interv. 2011:4:789-799.

67. Bourantas CV, Papafaklis MI, Lakkas L, et al. Fusion of optical coherence tomographic and angiographic data for more accurate evaluation of the endothelial shear stress patterns and neointimal distribution after bioresorbable scaffold implantation: comparison with intravascular ultrasound-derived reconstructions. Int J Cardiovasc Imaging. 2014:30:485-494

68. Kimura T, Kozuma $\mathrm{K}$, Tanabe $\mathrm{K}$, et al. A randomized trial evaluating everolimus-eluting Absorb bioresorbable scaffolds vs. everolimus- eluting metallic stents in patients with coronary artery disease: ABSORB Japan. Eur Heart J. 2015:36:3332-3342.

69. Ellis SG, Kereiakes DJ, Metzger DC, et al. Investigators Al. Everolimuseluting bioresorbable scaffolds for coronary artery disease. N Engl J Med. 2015;373:1905-1915.

70. Wykrzykowska JJ, Kraak RP, Hofma SH, et al. Investigators A. Bioresorbable Scaffolds versus Metallic Stents in Routine PCI. N Engl J Med. 2017;376:2319-2328.

71. Collet C, Asano T, Miyazaki $Y$, et al. Late thrombotic events after bioresorbable scaffold implantation: a systematic review and metaanalysis of randomized clinical trials. Eur Heart J. 2017;38:2559-2566.

72. Otsuka F, Pacheco E, Perkins LE, et al. Long-term safety of an everolimuseluting bioresorbable vascular scaffold and the cobalt-chromium XIENCE $\checkmark$ stent in a porcine coronary artery model. Circ Cardiovasc Interv. 2014;7:330-342.

73. Raber L, Brugaletta S, Yamaji K, et al. Very late scaffold thrombosis: intracoronary imaging and histopathological and spectroscopic findings. J Am Coll Cardiol. 2015;66:1901-1914. 
74. Finn AV, Nakazawa G, Joner M, et al. Vascular responses to drug eluting stents: Importance of delayed healing. Arterioscler Thromb Vasc Biol. 2007:27:1500-1510.

75. Foin N, Gutierrez-Chico JL, Nakatani S, et al. Incomplete stent apposition causes high shear flow disturbances and delay in neointimal coverage as a function of strut to wall detachment distance: implications for the management of incomplete stent apposition. Circ Cardiovasc Interv. 2014;7:180-189.

76. Holme PA, Orvim U, Hamers MJAG, et al. Shear-induced platelet activation and platelet microparticle formation at blood flow conditions as in arteries with a severe stenosis. Arterioscler Thromb Vasc Biol. 1997;17:646-653.

77. Martorell J, Santoma P, Kolandaivelu K, et al. Extent of flow recirculation governs expression of atherosclerotic and thrombotic biomarkers in arterial bifurcations. Cardiovasc Res. 2014;103:37-46.

78. Nam D, Ni CW, Rezvan A, et al. Partial carotid ligation is a model of acutely induced disturbed flow, leading to rapid endothelial dysfunction and atherosclerosis. Am J Physiol Heart Circ Physiol. 2009;297:H1535-H1543.

79. Bark DLJr, Ku DN. Wall shear over high degree stenoses pertinent to atherothrombosis. J Biomechanics. 2010;43:2970-2977.
80. Bark DL, Para AN, Ku DN. Correlation of thrombosis growth rate to pathological wall shear rate during platelet accumulation. Biotechnol Bioeng. 2012:109:2642-2650.

81. Fukumoto $\mathrm{Y}$, Hiro $\mathrm{T}$, Fujii $\mathrm{T}$, et al. Localized elevation of shear stress is related to coronary plaque rupture: a 3-dimensional intravascular ultrasound study with in-vivo color mapping of shear stress distribution. $J$ Am Coll Cardiol. 2008;51:645-650.

82. Brugaletta S, Radu MD, Garcia-Garcia HM, et al. Circumferential evaluation of the neointima by optical coherence tomography after ABSORB bioresorbable vascular scaffold implantation: can the scaffold cap the plaque? Atherosclerosis. 2012;221:106-112

83. Lane JP, Perkins LE, Sheehy AJ, et al. Lumen gain and restoration of pulsatility after implantation of a bioresorbable vascular scaffold in porcine coronary arteries. JACC Cardiovasc Interv. 2014;7:688-695.

84. Tateishi H, Suwannasom P, Sotomi $Y$, et al. investigators of the ABSORB Cohort B study. Edge Vascular Response After Resorption of the Everolimus-Eluting Bioresorbable Vascular Scaffold - A 5-Year Serial Optical Coherence Tomography Study. Circ J. 2016;80:1131-41.

85. Tamburino C, Latib A, van Geuns RJ, et al. Contemporary practice and technical aspects in coronary intervention with bioresorbable scaffolds: a European perspective. Eurolntervention. 2015;11:45-52. 